\title{
Thermodynamic work in inline piston gasoline engines as a function of crank angle
}

\author{
Aleksey Egorov ${ }^{1}$, Natalya Lysyannikova ${ }^{2}$, Yuri Kaizer ${ }^{2}$, Vasiliy Tyukanov $^{2, *}$, Alexander \\ Kuznetsov $^{3}$, Taalaibek Matkerimov ${ }^{4}$, Helena Tsygankova ${ }^{2}$, and Katharina Tretyakova ${ }^{2}$ \\ ${ }^{1}$ Volga State University of Technology, 424000, Yoshkar-Ola, 3, Lenin Square, Russia \\ ${ }^{2}$ Siberian Federal University, 660041, Krasnoyarsk, 82/6, Svobodny Avenu, Russia \\ ${ }^{3}$ Krasnoyarsk State Agrarian University, 660074, Krasnoyarsk, 2 Kirenskogo, Russia \\ ${ }^{4}$ Kyrgyz State Technical University, 720044, Bishkek, 66, Mira Avenu, Kyrgyzstan
}

\begin{abstract}
The purpose of this research work is to identify the laws of thermodynamic operation in the theoretical cycles of four-stroke inline piston gasoline internal combustion engines (ICE). The main results: dependence of the thermodynamic operation of the working body of ICE in theoretical cycles of four-stroke inline piston gasoline engines as a function of the angle of rotation of the crankshaft; regularities of uneven generation of positive thermodynamic operation in the theoretical cycle of four-stroke inline one-, two-, three -, five-cylinder piston gasoline ICE; regularities of the alternating character of thermodynamic operation in the theoretical cycles of inline four-stroke one -, two -, three -, four - and five-cylinder gasoline piston ICE; regularities of positive thermodynamic operation during the entire theoretical cycle of four-stroke inline six-and eightcylinder piston gasoline ICE; conditions for uniform pulsation of thermodynamic operation during the entire theoretical cycle of four-stroke inline piston gasoline ICE - the product of the crankshaft angle by the number of cylinders must be $720^{\circ}$ (four-cylinder inline with a crankshaft angle of $180^{\circ}$, six-cylinder inline with a crankshaft angle of $120^{\circ}$, eight-cylinder inline with a crankshaft angle of $90^{\circ}$ ).
\end{abstract}

\section{Introduction}

Piston internal combustion engines are one of the most common classes of rotational action engines. The tasks of improving the efficiency, reliability and durability of internal combustion engines and drives based they are crucial when creating competitive power plants based on them.

As shown by the analysis of open sources of information currently, work in the field of piston engine modeling is underway in the field of: modeling of fuel combustion processes $[1,9,19]$, modeling of gas dynamic processes both inside the cylinder and in the intake and exhaust systems $[2-6,8,11-13,15,16,30-32]$, modeling of heat transfer processes inside the cylinder [7, 14, 18, 20,26], modeling of fuel properties [10], modeling of friction processes in cylinder-piston group parts [17], modeling work of fuel systems [21],

\footnotetext{
*Corresponding author: vastuk85@mail.ru
} 
modeling for optimization purposes the design [22-25], modeling of shock interaction of the piston [27], modeling of engine cycles [28], modeling of the engine management system [29].

The review of scientific and technical sources, developed by leading Russian scientific centers energy engineering it is revealed that the theoretical justification of parameters of inline four-stroke piston gasoline internal combustion engines is based on some average per cycle of the thermodynamic parameters of the working body of ICE. This approach is quite acceptable in the design of wheeled and tracked vehicles, in which a constant consumption of mechanical work generated by a driven inline piston gasoline internal combustion engine is carried out. However, when designing process equipment driven by inline piston gasoline internal combustion engines, in which the mechanical work created by the engine is consumed not constantly, but in accordance with some law, in purpose to improve the efficiency of the "internal combustion engine - process machine" system, it is necessary to synchronize the maximum output of mechanical work by the engine with the maximum consumption of mechanical work by technological equipment (reciprocating compressors, electric generators, hydraulic pumps, etc.).

To date, open sources [33] have published approximate dependences of the change in the torque developed by a four-stroke inline piston gasoline internal combustion engine as a function of the angle of rotation of the crankshaft.

The purpose of the study is to identify the balance of thermodynamic operation in theoretical cycles of four-stroke inline piston gasoline internal combustion engines during the working cycle, that is, during two turns of the crankshaft as a function of the angle of rotation of the crankshaft.

To achieve this purpose, it is necessary to solve a number of the following tasks:

- development of mathematical models of thermodynamic operation in the working processes of four-stroke inline piston gasoline internal combustion engines;

- modeling the dependence of thermodynamic operation of four-stroke inline-piston gasoline internal combustion engines (ice): one -, two -, three -, four -, five -, six -, eightcylinder engines on the angle of rotation of the crankshaft during the last two speed rotation in Microsoft Excel.

\section{Mathematical modeling}

Consider the theoretical duty cycle of a four-stroke in-line gasoline piston internal combustion engine (figure 1).

In the first approximation, assume that the pressure in the over-piston space during the intake and exhaust process is equal to the atmospheric $p=p_{1}=p_{2}$.

Further thermodynamic parameters of the working medium (pressure $p$ and the volume $\mathrm{V}$ of the working body of ICE in space above the piston) in the characteristic points of the workflow, we will indicate the corresponding indexes and thermodynamic operation of A working body of ICE within the working process the start and end index. Using $\mathrm{n}_{1}$ denote the polytropic exponent is the compression of the working body of ICE through the $\mathrm{n}_{2}$ polytrope expansion of the working body of ICE. The degree of pressure increase in the process of 3-4 is denoted by $\lambda$. The compression ratio is equal to $\varepsilon$.

We will write down the dependencies for determining the current parameters of the working body of ICE at the characteristic points and thermodynamic operation in each of the working processes of a four-stroke gasoline piston engine according to [34].

Process 1-2: the work suction of the working body of ICE $A_{12}=p_{1}\left(V_{2}-V_{1}\right)$. Process 2-3: the work of compression of the working body of ICE 
$A_{23}=\frac{1}{n_{1}-1}\left(p_{3} V_{3}-p_{2} V_{2}\right)$, the pressure of the working body of ICE at point 3 is equal to $p_{3}=p_{2}\left(\frac{V_{2}}{V_{3}}\right)^{n_{1}}$, compression ratio $\varepsilon=\frac{V_{3}}{V_{2}}$. Process 3-4: the pressure of the working body of ICE at point 4 is equal to $p_{4}=\lambda p_{3}$. Process 4-5: the work expansion of the working body of ICE $A_{45}=\frac{1}{n_{2}-1}\left(p_{4} V_{4}-p_{5} V_{5}\right)$, the pressure of the working body of ICE at point 5 is equal to $p_{5}=p_{4}\left(\frac{V_{4}}{V_{5}}\right)^{n_{2}}$. Process 5-2: the process of reducing the pressure of the working body of ICE to atmospheric. Process 2-1: the work of Emission of fuel combustion products $A_{21}=p_{1}\left(V_{2}-V_{1}\right)$.

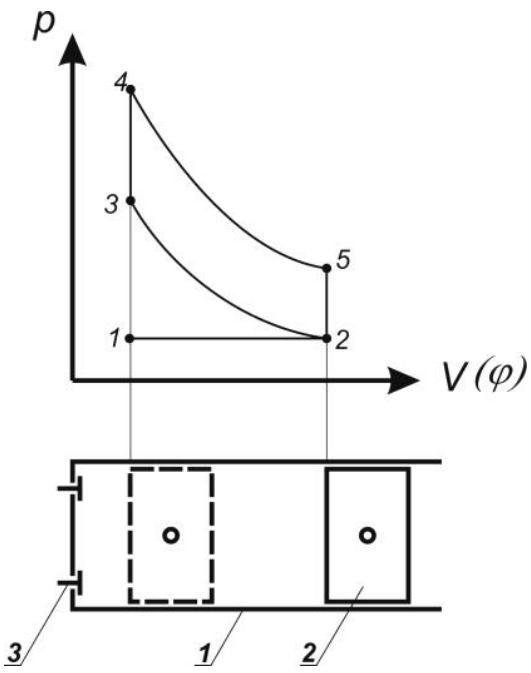

Fig, 1. The theoretical cycle of a four-stroke gasoline engine: 1 - Cylinder; 2 - Piston; 3 - Inlet and exhaust valves; Process 1-2 - Intake; Process 2-3 - Compression; Process 3-4 - fuel Combustion (pressure Increase); Process 4-5 - expansion of the working body of ICE; 5-2 - pressure drop When opening the exhaust valve; Process 2-1 - Emission of fuel combustion products.

From the point of view of the balance of operation piston machine work suction and work expansion of the working body of ICE have a positive value, as they are committed at the expense of the atmosphere and at the expense of internal energy of the working body of ICE accordingly. The compression work and the work of Emission of fuel combustion products are negative, so they require work on the working body of ICE.

The balance of operation in the theoretical cycle of a four-stroke piston gasoline engine is defined as:

$$
A=A_{12}-A_{23}+A_{45}-A_{21}
$$

\section{Processing the results obtained}

To identify the dependence of thermodynamic of the work in the theoretical cycle of a four stroke inline piston gasoline single cylinder engine on the angle of rotation of the crankshaft we perform mathematical modeling for a four stroke inline piston single cylinder engine based on the above dependencies, with the parameters: compression ratio $\varepsilon=10$, compression polytropy index $n_{1}=1.36$, expansion polytropy index $n_{2}=1.27$, the degree of pressure increase in the process of 3-4 $\lambda=4$ we take the recommendation [36], the total volume of the cylinder $V_{2}=0,417 \times 10^{-3} \mathrm{~m}^{3}$, working volume of the cylinder 
$V_{2}-V_{1}=0,375 \times 10^{-3} \mathrm{~m}^{3}$. According to the recommendation [33], the piston stroke $S_{n}=0,079 \mathrm{~m}$. and the cylinder diameter $\mathrm{D}=0.079 \mathrm{~m}$. are assumed to be equal to each other. The values $S_{p}$ and D are calculated based on the value of the working volume of the cylinder. Based on the value of $S_{p}$, we get the value of the crank radius $\mathrm{r}=0.0395 \mathrm{~m}$.

The simulation results are shown in figure 2 .

In the future, to simplify the presentation of the results obtained in inline piston multicylinder gasoline engines, we will assume that the thermodynamic processes of the first cylinder of a multi-cylinder engine coincide with the thermodynamic processes of a piston single-cylinder gasoline engine, and the thermodynamic processes in each subsequent cylinder are shifted relative to the thermodynamic processes of the first cylinder by the value of the angle between the cranks.

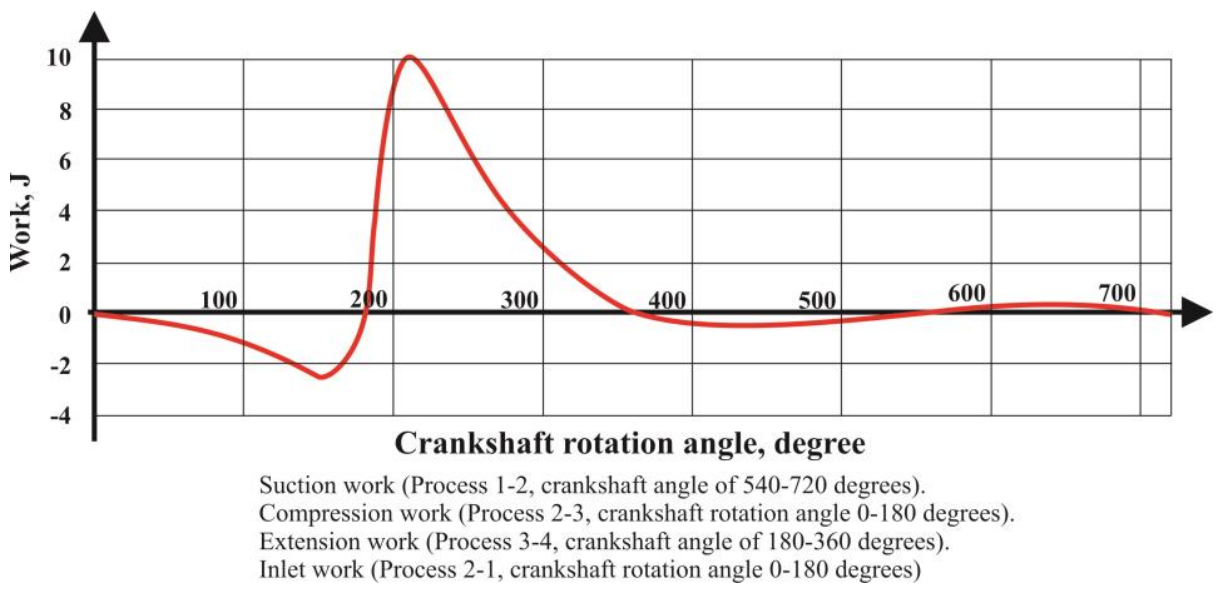

Fig. 2. Dependence of thermodynamic operation in the theoretical cycle of a four-stroke inline piston gasoline single-cylinder engine on the angle of rotation of the crankshaft.

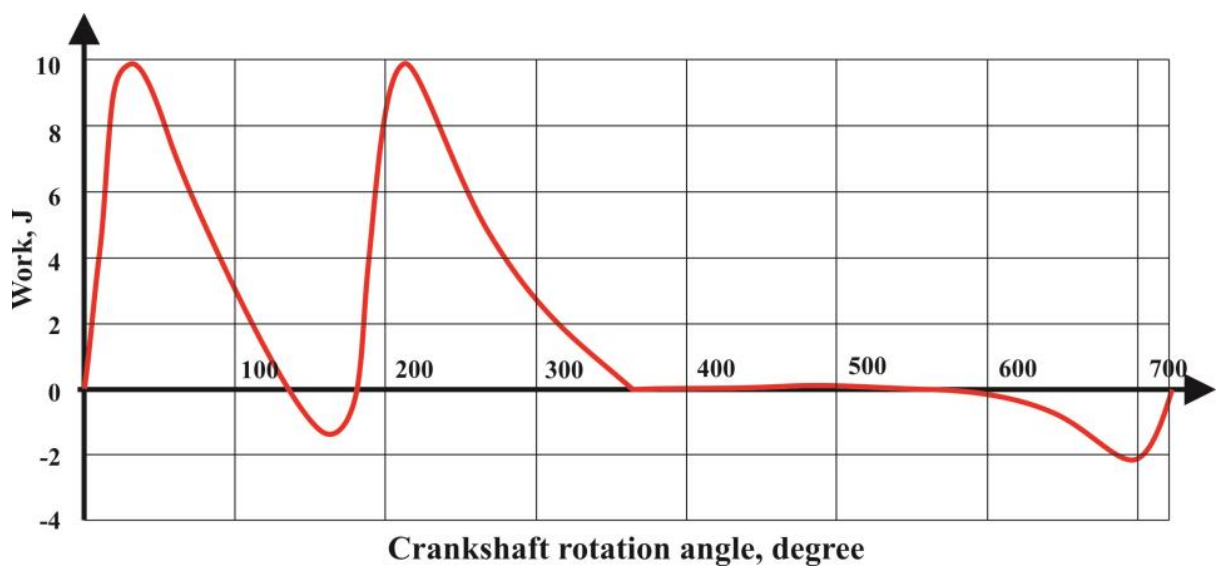

Fig. 3. Dependence of thermodynamic operation in the theoretical cycle of a four-stroke inline piston gasoline two-cylinder engine on the angle of rotation of the crankshaft.

Based on the data presented above, we perform a mathematical modeling of the dependence of thermodynamic operation in the theoretical cycle of a four-stroke inline 
piston gasoline two-cylinder engine on the angle of rotation of the crankshaft. The angle between the cranks is assumed to be 180 degrees according to the recommendation [37]. The modeling results are shown in figure 3.

Based on the data presented above, we perform a mathematical modeling of the dependence of thermodynamic operation in the theoretical cycle of a four-stroke inlinepiston gasoline three-cylinder engine on the angle of rotation of the crankshaft. The angle between the cranks is assumed to be 120 degrees according to the recommendation [37]. The modeling results are shown in figure 4.

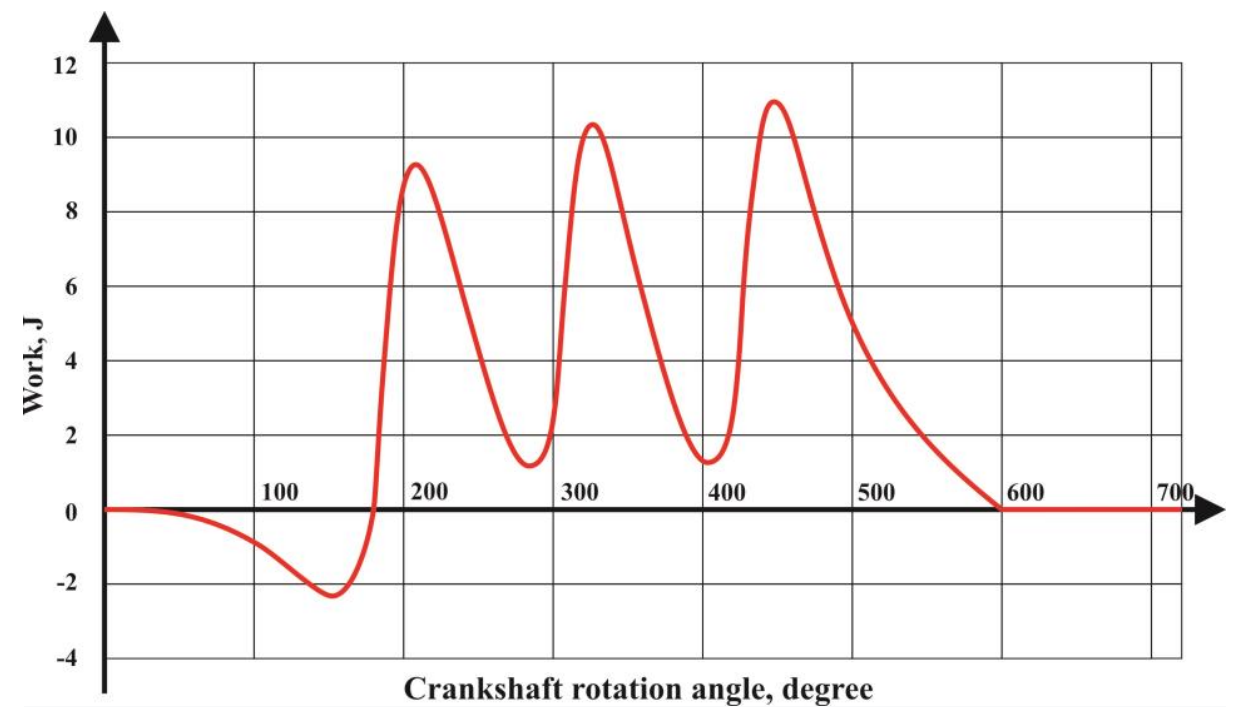

Fig. 4. Dependence of thermodynamic operation in the theoretical cycle of a four-stroke inline-piston gasoline three-cylinder engine on the angle of rotation of the crankshaft.

Based on the data presented above, we perform a mathematical modeling of the dependence of thermodynamic operation in the theoretical cycle of a four-stroke inlinepiston gasoline four-cylinder engine on the angle of rotation of the crankshaft. The angle between the cranks is assumed to be 180 degrees according to the recommendation [37]. The modeling results are shown in figure 5. 


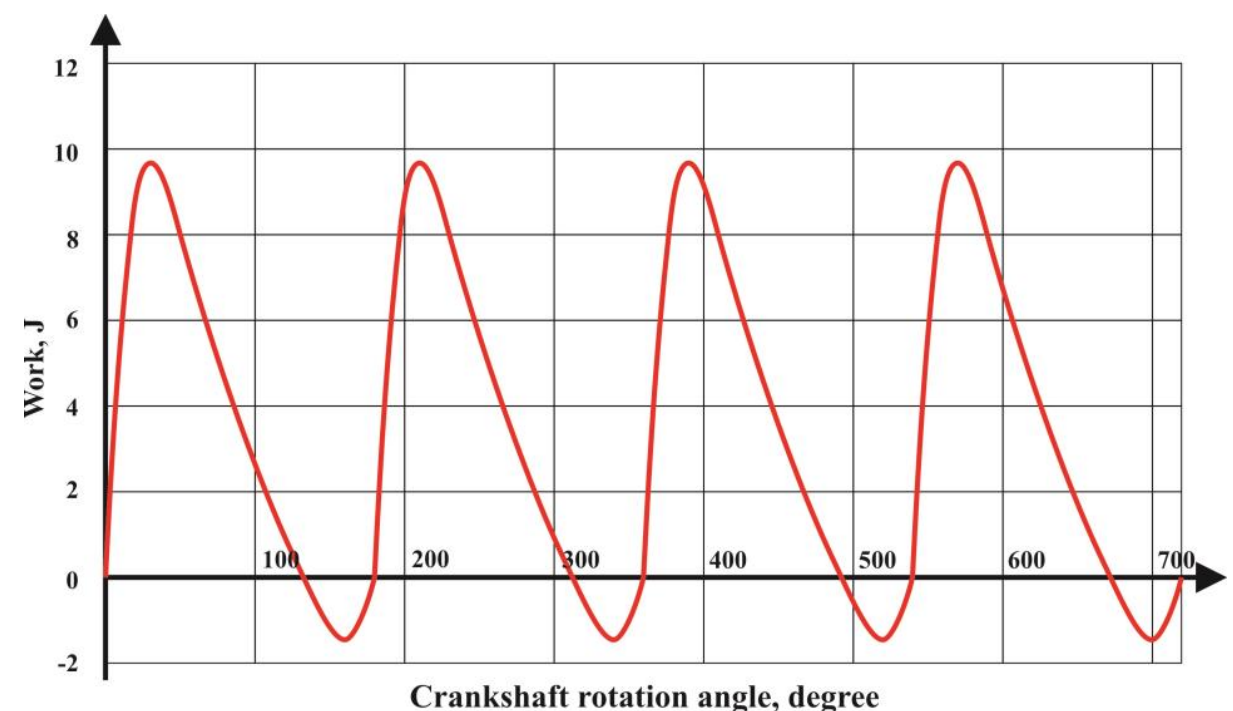

Fig. 5. Dependence of thermodynamic operation in the theoretical cycle of a four-stroke inline piston gasoline four-cylinder engine (the angle between the cranks $180^{\circ}$ ) on the angle of rotation of the crankshaft.

Based on the data presented above, we perform a mathematical modeling of the dependence of thermodynamic operation in the theoretical cycle of a four-stroke inlinepiston gasoline five-cylinder engine on the angle of rotation of the crankshaft. The angle between the cranks is assumed to be 72 degrees according to the recommendation [37]. The modeling results are shown in figure 6.

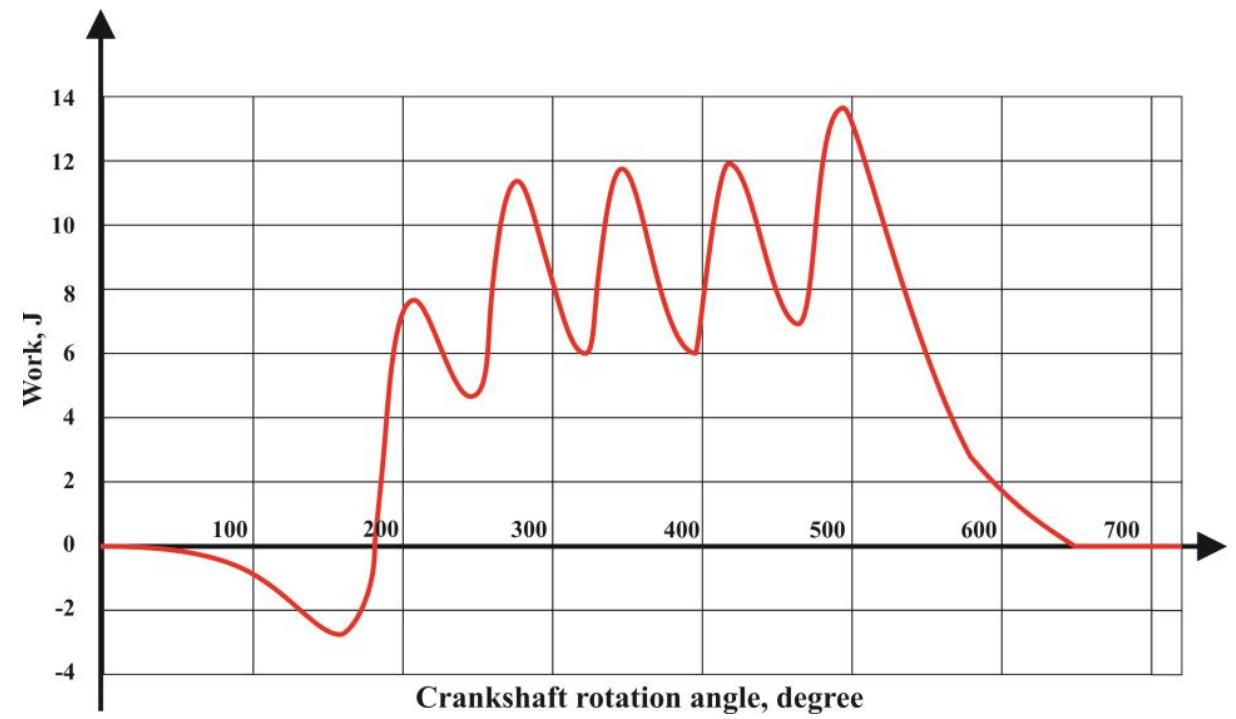

Fig. 6. Dependence of thermodynamic operation in the theoretical cycle of a four-stroke inline-piston gasoline five-cylinder engine (the angle between the cranks $72^{\circ}$ ) on the angle of rotation of the crankshaft. 
Based on the data presented above, we perform a mathematical modeling of the dependence of thermodynamic operation in the theoretical cycle of a four-stroke inline piston gasoline six-cylinder engine on the angle of rotation of the crankshaft. The angle between the cranks is assumed to be 120 degrees according to the recommendation [37]. The modeling results are shown in figure 7.

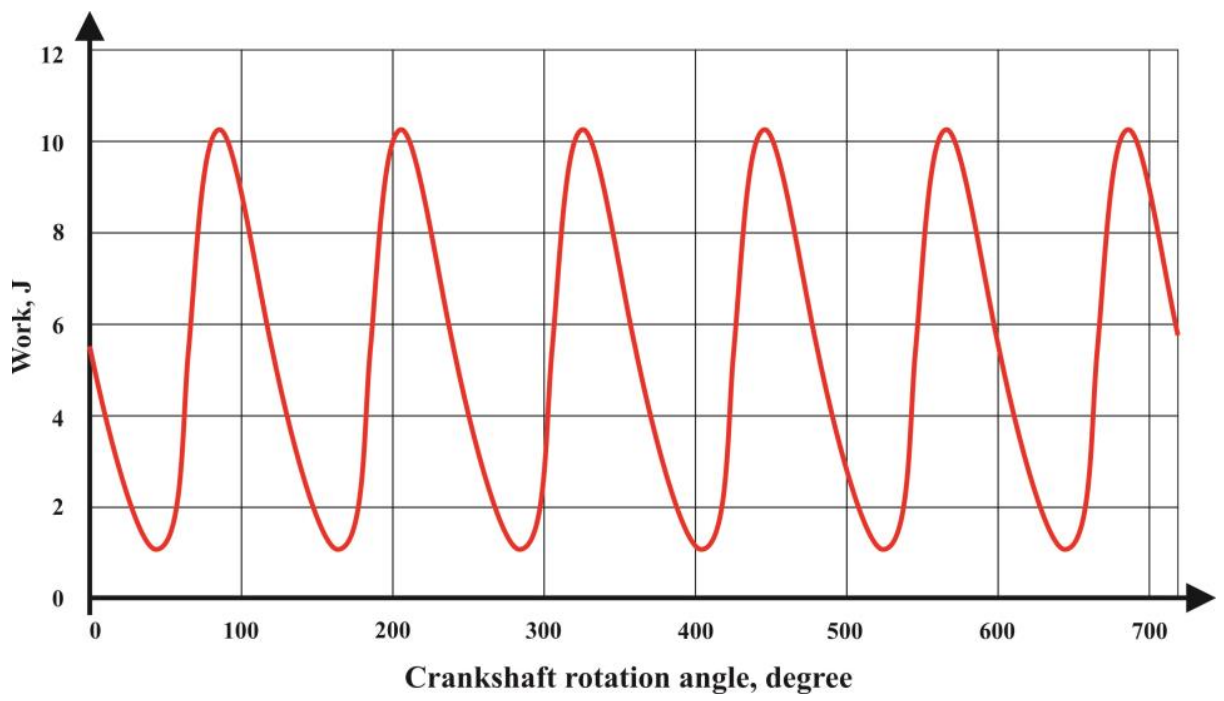

Fig. 7. Dependence of thermodynamic operation in the theoretical cycle of a four-stroke inline piston gasoline six-cylinder engine (the angle between the cranks $120^{\circ}$ ) on the angle of rotation of the crankshaft.

Based on the data presented above, we perform a mathematical modeling of the dependence of thermodynamic operation in the theoretical cycle of a four-stroke inlinepiston gasoline eight-cylinder engine on the angle of rotation of the crankshaft. The angle between the cranks is assumed to be 90 degrees according to the recommendation [37]. The modeling results are shown in figure 8.

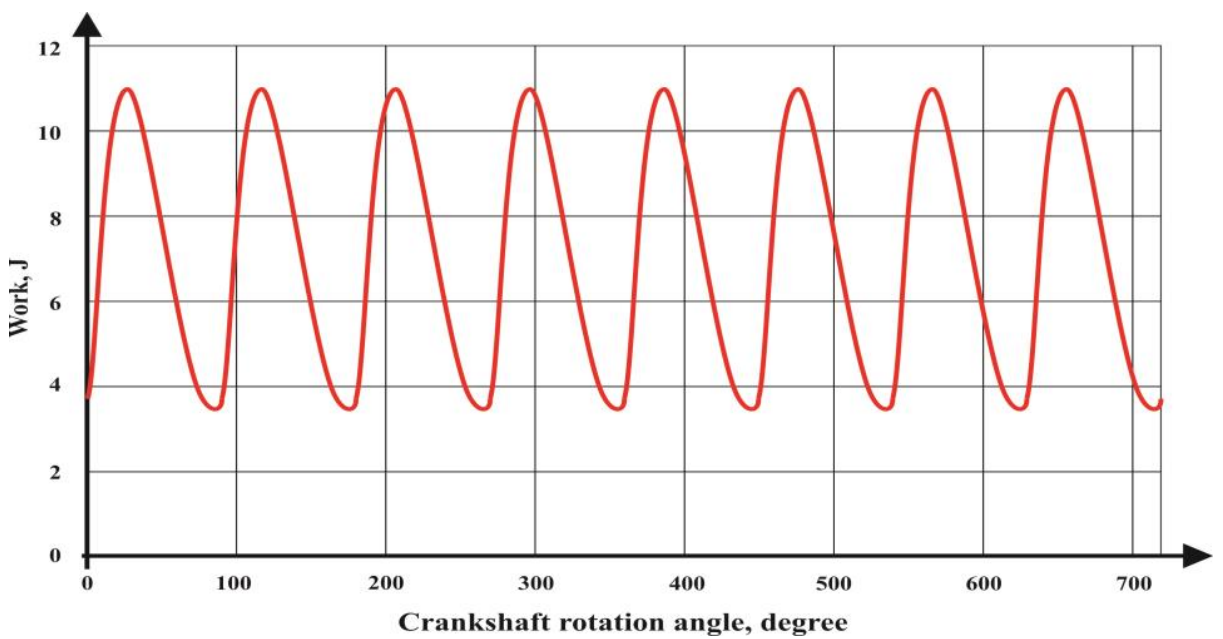

Fig. 8. Dependence of thermodynamic operation in the theoretical cycle of a four-stroke inline-piston gasoline eight-cylinder engine (the angle between the cranks $90^{\circ}$ ) on the angle of rotation of the crankshaft. 
The obtained results of mathematical modeling are partially correlated with the data presented in [33], in the form of changes in the torque developed by in-line multi-cylinder machines, mainly in the part of work developed by four, six and eight-cylinder in-line piston engines.

If the resulting mathematical modeling dependence of thermodynamic operation divided by the length of the business cycle and the angular velocity of the engine crankshaft during the implementation cycle, taking into account the indicated and mechanical efficiency of the engine you can get the torque dependences on the angle of rotation of the crankshaft.

\section{Conclusions}

Based on the results obtained, the following conclusions are made:

- the dependence of the thermodynamic operation of the working body of ICE in the working cycles of four-stroke piston inline gasoline engines as a function of the angle of rotation of the crankshaft is revealed;

- the results of mathematical modeling show the uneven development of positive thermodynamic operation in the working cycle of four-stroke inline one-, two-, three -, five-cylinder piston gasoline engines;

- the results of mathematical modeling show that positive thermodynamic operation is performed at a limited angle of rotation of the crankshaft in four-stroke inline one-, two-, three -, five-cylinder piston gasoline engines;

- the results of mathematical modeling show that the thermodynamic operation of inline four-stroke one -, two -, three -, four-and five-cylinder gasoline piston engines during the working cycle is alternating;

- the results of mathematical modeling show that positive thermodynamic performance during the entire operating cycle is observed only in four-stroke inline six-and eight-cylinder piston gasoline engines;

- the results of mathematical modeling show that for a uniform pulsation of thermodynamic operation during the entire working cycle of four-stroke inline piston gasoline engines, it is necessary that the product of the crank rotation angle by the number of cylinders is $720^{\circ}$ (four-cylinder inline with a crank rotation angle of $180^{\circ}$, six-cylinder inline with a crank rotation angle of $120^{\circ}$, eight-cylinder inline with a crank rotation angle of $90^{\circ}$ ).

\section{References}

1. S. Lapointe, K. Zhang, et al., Proceedings of the Combustion Institute 37 (1), 789-96 (2019) DOI: 10.1016/j.proci.2018.06.139

2. S.R. Gubba, R.S.Jupudi, et al., Journal of Solar Energy Engineering 140 (8), 082205 (2018) DOI: 10.1115/1.4039630

3. S. Buhl, F. Dietzsch, et al., Computers and Fluids 156, 66-80 (2017) DOI: 10.1016/j.compfluid.2017.06.023.

4. A. Berton, F. D'Orrico, M. Sideri, Energy Procedia 126, 979-86 (2017) DOI: 10.1016/j.egypro.2017.08.240

5. V.K. Krastev, L. Silvestri, G. Falcucci, Energies 10 (12), 2116 (2017) DOI: 10.3390/en 10122116

6. S.R. Gubba, R.S. Jupudi, et al., Internal Combustion Engine Division Fall Technical Conference 2 (8) (2017) DOI: 10.1115/ICEF20173527 
7. G. Decan, S. Broekaert, et al., Applied Energy 232 (11), 451-461 (2018) DOI: 10.4271/2017-24-0032

8. X. Yang, S. Keum, T.-W., Journal of Engineering for Gas Turbines and Power 138 (8) 081503 (2016) DOI: 10.1115/1.4032342

9. X. Zhen, Y. Wang, D. Liu, Energy Conversion and Management 109, 113-21 (2016) DOI: 10.1016/j.enconman.2015.11.061

10. B.S. Bevilacqua, N.P. Salau, SAE Technical Papers 9, 127081 (2015) DOI: 10.4271/2015-36-0505

11. M. Wentsch, A. Perrone, et al., SAE Technical Papers 9, 115954 (2015) DOI: 10.4271/2015-24-2469

12. X. Yang, S. Keum, T.-W. Kuo, Internal Combustion Engine Division Fall Technical Conference 2, ICEF (2015) DOI: 10.1115/ICEF2015-1022

13. X. Yang, S. Gupta, et al., Journal of Engineering for Gas Turbines and Power 136 (5), 051507 (2014) DOI: 10.1115/1.4026165

14. A. Agrira, D. Buttsworth, M.A. Said, Journal of Heat Transfer 136 (3), 031703 (2014) DOI: $10.1115 / 1.4025639$

15. A. Montorfano, F. Piscaglia, A. Onorati, Int. Journal of Computer Mathematics 91 (1), 62-70 (2014) DOI: 10.1080/00207160.2013.783207

16. P. Casoli, A. Gambarotta, et al., Energy Procedia 45, 839-48 (2014) DOI: 10.1016/j.egypro.2014.01.089

17. G. Offner, Tribology Transactions $56 \quad$ (3), 503-15 (2013) DOI: 10.1080/10402004.2012.763006

18. Z. Dong, G. Chen, et al., Journal of Huazhong University of Science and Technology (Natural Science Edition) 40 (9), 122-7 (2012)

19. E. Monteiro, J. Sotton, et al., Experimental Thermal and Fluid Science 35 (7), 1473-9 (2011) DOI: 10.1016/j.expthermflusci.2011.06.006

20. D.R. Buttsworth, A. Agrira, et al., Journal of Engineering for Gas Turbines and Power 133 (2), 022802 (2011) DOI: 10.1115/1.4001080

21. C. Huang, A. Lipatnikov, Modelling of gasoline and ethanol hollow-cone sprays using openFOAM. SAE Technical Papers (2011) DOI: 10.4271/2011-01-1896

22. E.J. López, E.J. Toth, et al., Computational Mechanics Research Trends, 365-452 (2010)

23. E.J. López, N.M. Nigro, Latin American Applied Research 40 (2), 175-84 (2010)

24. D. Buttsworth, 3rd International Conference on Energy and Environment: Advancement Towards Global Sustainability, 5398624, 343-7 (2009) DOI: 10.1109/ICEENVIRON.2009.5398624

25. D.-M. Ju, H. Meng, K. Han, Journal of System Simulation 21 (7), 1841-4 (2009)

26. D.R. Buttsworth, A. Agrira, et al., Proceedings of the ASME Internal Combustion Engine Division Fall Technical Conference, pp 413-9 (2009) DOI: 10.1115/ICEF2009-14056

27. P. Wang, Z.-X. Deng, et al., Journal of System Simulation 20 (20), 5476-9 (2008)

28. M. Wen, L. Lu, G. Jiang, Journal of Wuhan University of Technology (Transportation Science and Engineering) 31 (3), 476-9 (2007)

29. C.A. Rabbath, H. Desira, K., Proc. of the American Control Conf. 2, 1321-6 (2001) DOI: $10.1109 /$ ACC.2001.945907 
30. R.J. Pearson, M.D. Bassett, et al., Comprehensive charge-cooler model for simulating gas dynamics in engine manifolds. SAE Technical Papers (2000) DOI: 10.4271/200001-1264

31. H. Jasak, J.Y, Luo, et al., Rapid CFD simulation of internal combustion engine. SAE Technical Papers (1999) DOI: 10.4271/1999-01-1185

32. W.A. Woods, A. Allison, SAE Technical Papers 290445 (1977) DOI: 10.4271/770411

33. A.I. Kolchin, V.P. Demidov, Calculation of automobile and tractor engines: Manual for higher educational institutions, p, 496 (The higher school, 2008)

34. V.I. Krutov, S.I. Isaev, I.A. Kozhinov, Technical thermodynamics: The textbook for machine-building specialties of higher education institutions, p. 384 (The higher school, 1991)

35. V.I. Lukanin, K.A. Morozov, A.S. Khachiyan, Internal combustion engine In three books Book 1 Theory of working processes, p. 368 (The higher school, 1995)

36. D.N. Virubov, N.A. Ivashenko, V.I. Ivin, Internal combustion engine: The theory of the piston and combined engines The textbook for the highest technical educational institutions in "Internal combustion engines", p. 372 (Mashinostroenie, 1983)

37. D.N. Virubov, Internal combustion engine: Designing and calculation on durability of the piston and combined internal combustion engines The textbook for the highest technical educational institutions in "Internal combustion engines", p. 384 (Mashinostroenie, 1984) 